\title{
A screening clinic for relatives of patients with colorectal cancer in a district general hospital
}

\author{
S Carpenter, M Broughton, C G Marks
}

\begin{abstract}
A family cancer screening clinic was set up to screen and counsel subjects at above average risk of developing colorectal cancer. Criteria for referral were one first degree relative under 50 years or two of any age with colorectal cancer. Pedigree information was used to estimate lifetime risks of developing colorectal cancer and offer appropriate screening: colonoscopy for high risks (greater than 1 in 10), faecal occult blood testing for lower risks. One hundred and eleven subjects from 76 families were seen over four years. Forty two families gave a pedigree consistent with dominantly inherited non-polyposis colorectal cancer syndrome (HNPCC). Three subjects from one family were found to have familial adenomatous polyposis. Ninety two colonoscopies yielded 21 patients with polyps (12 had tubular adenomas, including one with early malignant invasion). Thirty three per cent (four of 12) of the tubular adenomas were beyond the reach of a flexible sigmoidoscope. Three hundred and forty two further high risk relatives were identified from the family history.

(Gut 1995; 36: 90-92)
\end{abstract}

Keywords: screening, colorectal cancer.

A monthly family cancer screening clinic was established in February 1989 to offer screening to those at above average risk of developing colorectal cancer. First degree relatives of affected subjects have a two to fourfold increase in risk of colorectal cancer ${ }^{12}$ and there are a number of dominantly inherited syndromes associated with colorectal cancer (familial adenomatous polyposis and two hereditary non-polyposis colon cancer syndromes, site specific colon cancer (Lynch type I), and cancer family syndrome where there is an increased risk of stomach, breast, uterine, and other cancers (Lynch type II)). These groups may account for

Department of Surgery, Royal Surrey County Hospital, Guildford, Surrey $S$ Carpenter $M$ Broughton C G Marks

Correspondence to: Dr $S$ Carpenter, GUTS Office, Level D, Royal Surrey County Hospital, Egerton Road, Guildford Surrey GU2 5XX.

Accepted for publication 12 April 1994 up to $20 \%$ of all colorectal cancers. ${ }^{3}$

TABLE I Lifetime risks of colorectal cancer in relatives of affected subjects

\begin{tabular}{ll}
\hline One first degree relative affected ( $>45$ years) & 1 in 17 \\
One first degree and one second degree affected & 1 in 12 \\
$\begin{array}{l}\text { One relative }<45 \text { years affected } \\
\text { Two first degree relatives affected }\end{array}$ & 1 in 10 \\
$\begin{array}{l}\text { Three first degree relatives affected (dominant } \\
\text { pedigree) }\end{array}$ & 1 in 2 \\
\hline
\end{tabular}

Population risk is 1 in 50.
The King's Fund Consensus statement emphasised the potential benefits of regular screening for those at high genetic risk. ${ }^{4}$

The clinic is based at a district general hospital serving a population of 189000 .

\section{Methods}

SETTING UP

A clinical assistant with a background in genetics and a research nurse, each working one session a week, were responsible for the organisation. A short talk was given to local general practitioners to introduce the clinic and the team joined the national Cancer Family Study Group to liaise with other groups.

INFORMATION LEAFLETS

These detailed why the patient had been invited, what family information might be required, the probable duration of the consultation (about three quarters of an hour), and a contact telephone number. Patient information material about colonoscopy, large bowel cancer, and those at higher risk was prepared.

RISKS AND SCREENING PROCEDURES

To estimate the risk to first degree relatives of patients with colorectal cancer, the figures calculated from Lovett's original pedigrees ${ }^{5}$ were used (Table I).

A subject was assessed as being a member of a hereditary non-polyposis colon cancer family (HNPCC) if they had three or more first degree relatives with colon cancer or one of the related adenocarcinomas.

Colonoscopic screening every four years was offered to those with a risk of 1 in 10 or greater (usually starting at age 30 years). Those with risks between 1 in 10 and 1 in 17 were offered screening by faecal occult blood testing. This was repeated after 12 months and thereafter every four years. ${ }^{6}$

\section{REFERRALS}

All patients attending our general surgical outpatient clinics, or admitted to the ward for whatever reason routinely had a brief family history taken. Those at sufficiently increased risk of developing colorectal cancer were referred to the family cancer screening clinic. Criteria for referral included a first degree relative below the age of 50 years or two or more first degree relatives of any age with colorectal cancer. 
TABLE II Results of colonoscopy screening compared with estimated risk of colorectal cancer in 111 subjects

\begin{tabular}{lccccc}
\hline Risk & $\begin{array}{l}\text { Number } \\
\text { counselled }\end{array}$ & $\begin{array}{l}\text { Number of } \\
\text { colonoscopies }\end{array}$ & $\begin{array}{l}\text { Number with } \\
\text { adenomas }\end{array}$ & $\begin{array}{l}\text { Incidence of } \\
\text { adenomas (\%) }\end{array}$ & $\begin{array}{l}\text { Average } \\
\text { age (y) }\end{array}$ \\
\hline 1 in $2^{\star}$ & $3^{\star}$ & $3^{\star}$ & $3^{\star}$ & $100^{\star}$ & 29 \\
1 in 2 & 62 & 56 & $11^{\star}$ & 20 & 46 \\
$<1$ in $2-1$ in 10 & 23 & 18 & 1 & 6 & 61 \\
$<1$ in 10 & 23 & 15 & 0 & 0 & 66 \\
Total & 111 & 92 & 15 & & \\
\hline
\end{tabular}

${ }^{\star}$ Risk of familial adenomatous polyposis; tone patient, severe dysplasia and early malignant invasion in $1 \mathrm{~cm}$ adenoma. and early malignant invasion. The tubular adenomas varied in size from $2 \mathrm{~mm}$ to $2.5 \mathrm{~cm}$ (six being over $1 \mathrm{~cm}$ in diameter). Four of them were found in the proximal colon. Eleven of 12 tubular adenomas were found in subjects at the highest ( 1 in 2) risk despite their lower average age (46 years). Overall incidence of adenomas in this highest risk group was $20 \%$ (11 of 56).

Three further patients with over 100 polyps each were found to have familial adenomatous polyposis.

Twenty four $(21 \%)$ patients also had abdominal symptoms including abdominal pain (12), rectal bleeding (6), and change of bowel habit (2). In the symptomatic group $8 \%$ (two of 24) had tubular adenomas, which is a similar incidence to the $11 \%$ (10 of 88 ) in the asymptomatic group.

All 92 subjects were screened by day case colonoscopy (apart from seven in the early months who had barium enema and flexible sigmoidoscopy - all screened negative). Only one patient is currently being screened by faecal occult blood testing, so far with negative results. The remaining seven lowest risk $(<1$ in 10$)$ subjects were not screened for a variety of reasons (too young (3), low risk (2), refused (2)).

Two hundred and forty relatives from 40 families were assessed as having a lifetime risk of 1 in 10 or more and some have started screening procedures in Guildford and other centres. of developing colorectal cancer. Thirty five subjects (from 22 families) showed a pedigree consistent with site specific colon cancer and 27 subjects (from 20 families) were compatible with cancer family syndrome. There were three subjects with familial adenomatous polyposis from one previously undiagnosed family.

Acceptance of screening by colonoscopy was $88 \%$ (77 of 88 ) in the higher risk category $(>1$ in 10$)$. Eleven patients were not screened. Five were cancer patients not due for their first screen (four years postoperatively), four were under 30 years, and two were not interested.

In the lowest risk category $(<1$ in 10$) 15$ subjects were, despite our protocol, eventually offered colonoscopy for a variety of reasons (reassurance and symptoms (8), reassurance (2), uncertain family history (5)).

The 92 screening colonoscopies yielded 30 polyps in 18 subjects (including two patients who had three polyps each and one who had six polyps). Histological examination (Table III) showed 12 tubular adenomas, one of which, of size $1 \mathrm{~cm}$, showed severe dysplasia

TABLE III Pathological features of 30 polyps

\begin{tabular}{llll}
\hline & Total & Risk 1 in 2 & Risk $<1$ in 2 \\
\hline Number of polyps & 30 & 23 & 7 \\
Histology & & & \\
$\quad$ Tubular adenoma & $12^{\star}$ & $11^{\star}$ & 1 \\
$\quad$ Metaplastic polyps & 8 & 5 & 3 \\
Juvenile polyp & 1 & 1 & 0 \\
$\quad$ Not retrieved (<2 mm) & 9 & 6 & 3 \\
Multiple polyps (3 or more) & 3 & 3 & 0 \\
Large polyp (>1 cm) & 6 & 6 & 0 \\
Proximal to splenic flexure & 4 & 4 & 0 \\
\hline
\end{tabular}

^One adenoma with severe dysplasia and early malignant invasion.

\section{Discussion}

The large number of subjects assessed as having a dominantly inherited, hereditary non-polyposis, colorectal cancer syndrome surprised us. Forty two families were identified in four years and although this was a highly selected group, they were found among the patients of one general surgeon. Only one new familial adenomatous polyposis family was ascertained.

The overall incidence of adenomas found at colonoscopic screening correlated well with the risk categories, being highest $20 \%$ (11 of 56$)$ in those at most risk ( 1 in 2 ) and lowest $0 \%$ ( 0 of $15)$ in those at least risk ( $<1$ in 10). This was despite the much lower average age (46 years) in the highest risk group (Table II). How this compares with the incidence in the general population is difficult to assess. Few control studies have used colonoscopic screening in a young, low risk group. The ethics of such screening in young, asymptomatic, low risk subjects is debatable.

The number of additional colonoscopies generated by the clinic was manageable, at around two procedures a month. The annual cost for the clinic, including salaries, was around $£ 4000$ but the resulting screening colonoscopies with their day case admission costs increased the total annual expenditure to just over $£ 12000$. It may be felt that the yield from all this work was rather low, in finding 12 patients with adenomas and only one colorectal cancer. An unforeseen but welcome benefit 
of the family cancer screening clinic, however, was the reassurance that it provided to a small but extremely anxious group of people. Most, if not all, had already assessed themselves as being at high risk because of their affected relatives. They were relieved to have a chance of discussing their fears and to make a personal screening plan for the future. The value of all this is difficult to quantify.

In an attempt to reduce the costs it may prove necessary to select our patients more carefully. Ninety two per cent (11 of 12) of the adenomatous polyps, including the colorectal cancer were found in patients at highest, 1 in 2 risk. By targeting screening to this group we would save over a third of our colonoscopy costs. Reducing the total annual expenditure to just over $£ 9000$. If colonoscopic screening was replaced by lower cost flexible sigmoidoscopy, however, we would have missed a third (four of 12) of our adenomas.

It is too early to tell whether flexible sigmoidoscopy would have been a suitable and cheaper alternative to colonoscopy in the lower risk group ( $<1$ in 2 ) as we have, as yet, found only one adenoma in this group.

From this small study we have shown that a family cancer screening clinic can successfully be run in a district general hospital given interested staff and a little additional expertise. Invasive and costly large bowel screening can successfully be targeted at those at high risk.

The authors thank Susan Caffarey, Research Sister, for secretarial help.

This study received support from GUTS (Guildford Undetected Tumour Screening) and the Imperial Cancer Research Fund.

1 Lovett E. Family studies in cancer of the colon and rectum. Br f Surg 1976; 63: 13-8.

2 Anderson DE. An inherited form of large bowel cancer. Cancer 1980; 47: 1103-7.

3 Lynch PM, Lynch HT, Harris RE. Hereditary proximal colonic cancer. Dis Colon Rectum 1977; 20: 661-8.

4 Cancer of the colon and rectum: the Seventh King's Fund Consensus Statement. Br F Surg 1990; 77: 1063-5.

5 Slack J. Family cancer syndromes. f R Soc Med 1989; 82: 233-4

6 Caffarey SM, Broughton CIM, Marks CG. Faecal occult blood screening for colorectal neoplasia in a targeted high risk population. $B r \mathcal{F}$ Surg 1993; 80: 1399-400. 